Pensamiento Crítico Vol. 19 № 2, pp. 39-64

\title{
Dumping y subsidios en las exportaciones chinas: El caso textil peruano
}

\author{
Dumping and subsidies of textiles \\ and apparel from China in Peru
}

Rubén Berríos*

\section{RESUMEN}

Se apunta a dilucidar de que manera las prácticas comerciales en las relaciones bilaterales Perú-China afectan la competencia justa. Se examina el tema de dumping y otras prácticas desleales en las relaciones comerciales entre los dos países y la manera en que podría afectar negativamente, en particular el sector textil y confecciones de la economía peruana. El ingreso de productos chinos a precios subvalorados ha perjudicado a varias empresas de tela y confecciones de prendas, obligando a estas a retirarse debido a las fuertes perdidas. China, desde la creación de Indecopi, ha sido objeto del mayor número de quejas en casos antidumping.

Palabras clave: Competencia desleal, dumping, subsidios, piratería, salvaguardas, Indecopi.

* Profesor de economía en Lock Haven University, Pennsylvania. Es autor de Contracting for development (2000) y de tres docenas de artículos en revistas especializadas y capítulos en libros. Trabaja temas de comercio internacional y desarrollo económico. Dirección: Department of Business, Lock Haven University, Lock Haven, PA 17745, USA. E-mail: rberrios@lhup.edu. 


\title{
Pensamiento Crítico Vol. 19. No 2
}

\begin{abstract}
This article examines dumping and subsidies and other unfair trade practices in Peru's commercial relations with China. It discusses how this negatively affects, particularly the textile and apparel sector in Peru's economy. The influx of Chinese products at substantially reduced prices has affected many firms in this sector obligating many of them to exit the market after posting significant losses. Since the creation of the regulatory agency Indecopi, China has been the country most cited for cases of dumping and other trade violations.
\end{abstract}

Keywords: Dumping, subsidies, unfair trade practices, China price, Indecopi.

El crecimiento del intercambio comercial entre Asia-Pacífico y el Perú se ha visto estimulado no solo por el impresionante crecimiento y participación de China en el comercio mundial sino, más aún, por el Tratado de Libre Comercio (TLC) firmado por ambos países en noviembre de 2009. No obstante, aunque los beneficios de un mayor intercambio comercial con China son muy conocidos por su enorme potencial económico, las importaciones provenientes del gigante asiático no siempre han sido vistas de manera favorable por algunos sectores del empresariado peruano (Bustamante 2004; Infante 2002, 2004; Mincetur 2007).

Es en la década de los noventa, cuando Perú, Chile y México logran una ventaja de negocios al abrirse hacia la región del Asia-Pacífico a través de su participación en el Foro de Cooperación Económica Asia-Pacífico (APEC). En el caso del Perú, Alberto Fujimori (1990-2000) fue quien, respaldado por su origen japonés, había hecho preponderantes los vínculos diplomáticos y comerciales con dicha región (Berríos 2010; Mann 2006).

El auge de la cooperación económica Perú-China también empezó a inicios de esa década; lapso caracterizado por una relación comercial más abierta, donde el valor y volumen de las exportaciones hacia China se incrementaron significativamente, pero que es, a su vez, cuando se ha dejado sentir el peso del ingreso masivo de productos chinos al Perú. Desde un inicio esto generó preocupación en algunos sectores del mercado peruano, especialmente en el textil. En ese sentido, algunos expertos han señalado tempranamente que esta apertura comercial ha sido perjudicial para las empresas peruanas (Bustamante 2004; Mendoza 2010; Mincetur 2009; Torres 2010), ya que no pueden competir con empresas chinas que operan con costos más bajos y aplican mecanismos de comercio vedados por la Organización Mundial de Comercio (OMC). 


\section{Rubén Berríos}

Siendo pocos los investigadores peruanos que se han ocupado del asunto, nos proponemos investigar si estas prácticas comerciales de exportación de productos chinos al Perú son efectivamente desleales, y si atentan contra la libre competencia. A excepción del trabajo de Webb, Camminati y León (2005), en la revisión bibliográfica solo hemos encontrado algunas alusiones al respecto.

En el análisis haremos énfasis en el sector textil que, además de ser el más perjudicado, es el que cuenta con relativa información estadística y el que mayores procesos ha iniciado contra las prácticas comerciales chinas.

\section{Consideraciones teóricas}

En la teoría del comercio internacional se consideran prácticas desleales a las acciones, políticas y prácticas que usan los países al exportar y que son consideradas injustas, no razonables o discriminatorias para el país receptor. Competencia desleal es el término genérico que se utiliza para todas estas prácticas que perjudican el libre comercio y se refiere a las distorsiones en el sistema mundial de comercio; las que podrían tomar diversas formas. Estas prácticas que se pueden manifestar en forma de dumping, subsidios, infracción de los derechos de propiedad intelectual o piratería, incorrecta clasificación arancelaria de mercancías, tergiversación en valor de facturas, manipulación de la moneda y otros tipos de hechos que van en contra del comercio justo; las que, sin duda, dan a la empresa extranjera una ventaja en el mercado nacional. Algunos países receptores contrarrestan formalmente estas prácticas mediante la imposición de aranceles, cuotas u otras barreras, con la cual generan nuevas distorsiones al libre comercio. En realidad, no existe país que sea totalmente liberal en su comercio, en especial cuando se trata de defender el mercado interno.

El dumping es una práctica comercial por la cual las empresas de un país exportan sus productos a un precio que está por debajo del que normalmente se vende en su propio mercado, o cuando el precio es menor al costo promedio de su producción. Esta forma de comercio implica dominación de precios, ya que la venta está por debajo de su valor justo y la OMC la considerada perjudicial por el daño que causa a ese sector de producción del país importador, al que puede llevar a la quiebra de sus empresas. En este sentido, esta práctica desleal del comercio internacional crea distorsiones y perjudica al país importador (Viner 1966). Por lo tanto, el país importador tiene derecho a aplicar un arancel o medida antidumping cuando la empresa extranjera está haciendo uso de aquellas prácticas. 


\section{Pensamiento Crítico Vol. 19. № 2}

La economía del dumping se puede explicar numéricamente ${ }^{1}$ o con un gráfico. Supongamos que el gráfico representa el mercado de textiles y confecciones en el Perú y el país exportador es China. Bajo las condiciones de comercio libre el precio de textiles a nivel mundial es PM y se importa la cantidad MN. Si China baja el precio de los textiles a $\mathrm{P}_{1}$, los chinos estarían haciendo dumping en el mercado peruano.

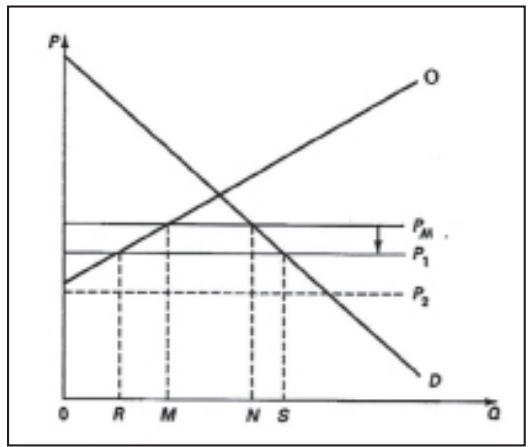

Con base en este ejemplo, si el precio de dumping es $\mathrm{P}_{1}$, ¿Cuál sería su efecto? En este caso, los consumidores son los que se benefician pero la industria nacional sería la perjudicada. El argumento simple es que el nivel de bienestar se incrementaría, pero resulta inaceptable para la industria textil y de confecciones del Perú, porque afectaría una importante fuente de generación de empleo.

A nivel teórico, el dumping se puede clasificar como persistente, predatorio o esporádico. Persistente es cuando este es usado continuamente para maximizar utilidades. Sin embargo, este comportamiento de vender en el exterior por debajo de su costo, no puede persistir a largo plazo porque el productor sufriría pérdidas; a menos que el gobierno otorgue un subsidio.

Predatorio es la venta temporal del producto por debajo de su costo de producción con la intención de desplazar al productor extranjero y forzar a que éste cierre. Una vez que esto se consiga se incrementa gradualmente el precio aprovechando el poder de mercado adquirido por la empresa extranjera. El caso de dumping predatorio se puede visualizar en el gráfico si el precio es reducido a $\mathrm{P}_{2}$. En este caso, si hay un argumento válido para proteger a la industria nacional.

Dumping esporádico ocurre cuando el productor (o gobierno) extranjero tiene un exceso del producto de exportación. La idea es descargar temporalmente el exceso del producto sin tener que reducir el precio del país de origen. Este tipo de dumping puede tener efectos adversos al afectar a los productores nacionales ya que genera malestar e incertidumbre en la industria.

1 ¿Por qué hay empresas extranjeras que hacen uso del dumping? A primera vista, vender fuera a precios por debajo del costo promedio de producción no es rentable. ¿Es esto cierto? No necesariamente. Puede ser ren- 


\section{Rubén Berríos}

Aunque generalmente el dumping tiene una connotación negativa, los defensores del libre mercado sostienen que vender productos importados a precios bajos (precios de dumping) beneficia a los consumidores y que las medidas proteccionistas generan consecuencias contraproducentes (Viner 1966). Los adversarios de esta tesis argumentan que esa mayor cantidad de importaciones de determinados productos podría ser la causa principal del daño o una amenaza para la industria nacional, aunque reconocen que asumir una forma de proteccionismo tiene como resultado reducir los beneficios al consumidor (Appleyard y Field 2001; Carbaugh 2013). También se critica al complicado proceso de investigación para calcular los márgenes del dumping $y$, finalmente, que las medidas antidumping no mejoran los términos de intercambio y que a veces son usadas más de lo necesario (Li, 2007).

table vender a precios bajos en el exterior aún si es por debajo del costo promedio. Para esto podríamos hacer uso de un ejemplo numérico. Supongamos que la empresa extranjera tiene los siguientes costos:

Precio unitario local $=\$ 25$

Costo unitario variable (costo marginal) $=\$ 10$

Costos fijos $=\$ 100$

Cantidad de venta local $=10$

Precio unitario de exportación $=\$ 15$

Cantidad de exportación $=10$

Las utilidades recibidas por vender en el mercado local son:

Ingresos - costo variable - costo fijo $=$ utilidades

$(\$ 25 \times 10)-(\$ 10 \times 10)-\$ 100=\$ 50$

$250-100-100=\$ 50$

Costo total $*$ costo variable + costo fijo (el costo se grafica con signo - )

$(-100)+(-100)=-200$ y el costo promedio local: $-200 / 10$ unidades $=\$-20$

Supongamos que la empresa vende al exterior adicionalmente 10 unidades a $\$ 15$ por unidad (por debajo del costo promedio de producción):

Ingresos (venta) - costo variable - costo Fijo $=$ utilidad o beneficio

$[(\$ 25 \times 10)+(\$ 15 \times 10)]-[(\$ 10 \times 10)+(\$ 10 \times 10)]-[\$ 100+0]=\$ 100$

$(250+150)-(100+100)-(100+0)=\$ 100$

$400-200-100=\$ 100$

Explicación: Como el costo fijo ya se aplicó a las 10 primeras unidades locales, el nuevo costo promedio (marginal) de las siguientes unidades solo será el costo variable $(\$ 10 \times 10=\$ 100)$ por lo que el precio al exterior que era aparentemente menor al costo promedio de $\$ 20$, será solo de $\$ 10$. ( $\$ 100+0$ costo fijo) / 10 unidades $=\$ 10$ por no existir ya los costos fijos (0), así que el nuevo costo total será (costo variable total: $\$ 10$ x las nuevas: 10 unidades $+\$ 10$ x por las unidades anteriores) por lo que, el costo variable total será: $\$ 200$ que divididos entre las 20 unidades totales (10 unidades locales +10 unidades de exportación) nos da el nuevo costo promedio de $\$ 10$, como indica la ecuación, con lo cual, el precio de 15 producirá nuevas utilidades, ya que 15 que es el precio, menos 10 que es el nuevo costo variable (marginal), nos da una nueva utilidad unitaria de $\$ 5$, por lo que el resultado se incrementa en $\$ 5$ de utilidad unitaria $\times 10$ unidades nuevas vendidas $=\$ 50$ de nueva utilidad; con lo cual, las utilidades totales serán $\$ 100$ (los 50 obtenidos por exportaciones, más los 50 obtenidos localmente). 


\section{Pensamiento Crítico Vol. 19. No 2}

De acuerdo a las reglas establecidas por la OMC, el país importador tiene derecho de aplicar medidas antidumping o salvaguardias cuando la empresa extranjera perjudica a la nacional por el uso del dumping. Esto se hace después de hacer un análisis técnico previo para medir sus efectos (Salvatore, 2007). El propósito de la medida es subir el precio del producto como una medida de defensa. En los casos de competencia perfecta y libre mercado el Estado no debería proteger a ningún sector; pero este puede intervenir cuando las empresas nacionales no están en condiciones de igualdad de competencia como resultado del dumping. En el caso de las empresas afectadas, estas se ven obligadas a presentar denuncias y solicitar protección cuando la industria es amenazada por importaciones que se venden a precios injustificadamente bajos. La medida de defensa, entonces, es usada para contrarrestar la diferencia del precio de importación con el precio de venta local.

Se debe precisar que mientras que el dumping es considerado una política de las empresas, los subsidios lo son del Estado. Los subsidios de exportación son pagos a la empresa exportadora. En general, los subsidios son un tipo de práctica ilegal promovida por los Estados para promover exportaciones y venderlas a precios artificialmente bajos. Estos se usan como un incentivo para exportar y su efecto adverso es la reducción de los precios de los productos locales. Pueden tener las siguientes formas: exoneración de impuestos, trato preferencial por exportaciones, bajos impuestos prediales, exoneración de impuestos por producir en zonas económicas especiales, o reembolso por exportaciones.

Otro aspecto de la competencia desleal se manifiesta en la manipulación de la moneda que resulta ser un tipo de subsidio que pone al socio comercial en desventaja. Un ejemplo de ello es el hecho que las exportaciones chinas se han estimulado porque el valor del yuan se ha mantenido muy por debajo de su valor real. El FMI (Fondo Monetario Internacional), el Departamento del Tesoro de los EE.UU. y estudios del FED estiman que el yuan chino está subvaluado en relación con el dólar americano. La manipulación de la moneda por el gobierno chino ha contribuido al incremento del déficit comercial de sus principales socios comerciales.

\section{El comercio chino-peruano y el TLC}

En las últimas dos décadas el comercio entre Perú y China ha experimentado un rápido crecimiento. En el periodo 1990-2000 las exportaciones del Perú crecieron de 


\section{Rubén Berríos}

US $\$ 34.6$ millones a US $\$ 445$ millones (12.9 veces), y en 2010 superaron los US $\$ 10.5$ mil millones (ver gráfico 1). Hasta fines de 2012, el Perú había mantenido un superávit comercial con China, pero al año siguiente este hecho cambió y podría cambiar aún más en la medida que las exportaciones peruanas demuestran mayor volatilidad, mientras que las importaciones de productos chinos han crecido a un ritmo casi constante.

En 2005, China se convirtió en el segundo socio comercial del Perú y en el mercado más grande para las exportaciones peruanas, y es desde 2011 su socio comercial más importante. Aun así, las exportaciones hacia aquel país demuestran poca diversidad (en la actualidad esto está cambiando) y bajo valor agregado, porque se concentran en minerales y harina de pescado. Estos dos rubros en 2013 constituían aproximadamente el $98 \%$ de las exportaciones peruanas a China.

\section{GRÁFICO 1}

Comercio Perú-China

(US\$ millones)

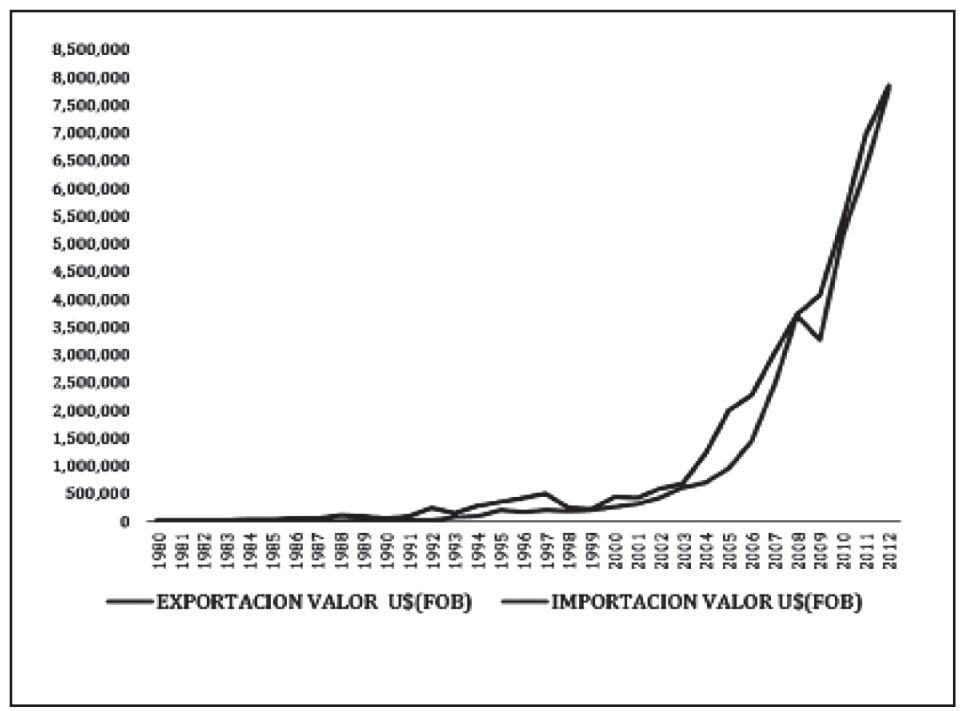

Fuente: Aduanas, Mincetur, SUNAT, varios años 


\section{Pensamiento Crítico Vol. 19. № 2}

Por el lado del Perú, las importaciones de los productos chinos demuestran una mayor diversificación: maquinaria y equipos, partes y accesorios, electrodomésticos, calzado, ropa, etc., con un mayor contenido de tecnología y una alta tasa de crecimiento, especialmente en la última década. Es justamente en los productos importados mencionados, como calzado y textiles donde el Perú podría competir con éxito en el mercado internacional. Por esta razón es que China es vista por algunos empresarios como una potencial amenaza (Infante 2004; Campodónico 2008; Mendoza 2010; Torres 2010).

En 2009, el Perú se convertía en el segundo país latinoamericano en firmar un TLC con el gigante asiático. Las negociaciones para firmarlo no fueron fáciles, ya que el Perú se exponía a la competencia de productos chinos baratos que podrían invadir su mercado. Torres-Zorrilla y Woll (2007) enfatizaron que el "objetivo general del TLC con China debe ser diversificar los productos y servicios peruanos en el mercado chino, y la presencia de empresas nacionales en los mercados chinos". Si bien la aseveración es correcta, a cuatro años de su implementación, Wise (2012) señala que el acuerdo es amplio pero poco profundo. El mayor impedimento es que la agenda comercial sigue siendo la misma. El Perú exporta commodities y China productos manufacturados (González-Vicente, 2012). Otro impedimento es que los empresarios peruanos desconocen el mercado y la cultura chinas, tienen poca experiencia en tomar riegos en un mercado geográficamente lejano, y carecen de recursos e información para dar ese salto que antes no ha sido intentado (Quispe, 2009). De otro lado, González-Vigil (2009) anota que a primera vista el acuerdo ofrece las protecciones necesarias para un cierto número de productos, lo que podría designarse como 'protección negociada'.

Al respecto, al empezar las negociaciones, China le exigía al Perú que renunciara a los mecanismos de protección que otorga la OMC. No obstante, durante el curso de las negociaciones algunos productos peruanos fueron excluidos de estos mecanismos, es decir, fueron protegidos (González-Vigil 2009; Mincetur 2007; Sanborn y Torres 2009).

\section{Indecopi y la defensa comercial}

A principios de los años noventa, debido a la coyuntura de nuestro comercio internacional y a los reclamos sostenidos de los sectores perjudicados, el Gobierno 


\section{Rubén Berríos}

peruano tomó la iniciativa de comenzar investigaciones, normar y resolver casos sobre dumping y subsidios. Así, en 1993, creó el Indecopi (Instituto Nacional de Defensa de la Competencia y de la Protección de la Propiedad Intelectual) con el fin de mantener la igualdad de condiciones en el comercio de libre mercado en el Perú y aplicar las normas de defensa comercial. Una pieza clave en este organismo fue la Comisión de Fiscalización de Dumping y Subsidios (CFDS). Las medidas antidumping que esta impuso fueron a solicitud del sector textil/vestimenta (Webb, Camminati y León 2005). La piratería -que también es competencia de Indecopi- por ser mucho más trabajosa de comprobar es, hasta hoy, mucho más difícil de combatir.

Si la denuncia es considerada válida, el Indecopi le impone una medida antidumping, equivalente al margen de diferencia entre el precio actual y el precio no lesivo del producto importado. Es decir, la medida antidumping puede ser como máximo equivalente al margen de dumping determinado durante la investigación y solo podría ser implementada si existiese prueba de que el precio del producto importado ha afectado negativamente a la industria nacional. Sin embargo, demostrar que se trata de un precio no competitivo es difícil porque requiere de tiempo y recursos, al tratarse de precios relativos. Así, un proceso que debería resolverse en nueve meses podría, en algunos casos, durar hasta dieciocho meses para que se resuelva.

Entre los casos más conocidos y mencionados de denuncias por dumping, se encuentran el sector textil y vestimenta, compuesto por empresas establecidas y las de 'Gamarra', zona comercial ubicada en el distrito de La Victoria, en Lima. Esta última es un emporio de fábricas de confección que producen formal e informalmente, con miles de operarios en la industria textil de confecciones y del vestido. Infante (2002) señala que esta "es la concentración empresarial más grande que tiene el Perú". En los últimos años, los empresarios formales de Gamarra han presentado muchas quejas al Indecopi por intermedio del Comité Textil de la SIN (Sociedad Nacional de Industrias), pues se han visto afectados por la entrada de productos a precios de dumping, subvaluados $\mathrm{y}$, en muchos casos, por contrabando.

El ingreso constante de prendas y textiles chinos ha tenido un crecimiento importante, estableciéndose como el principal abastecedor de ropa en el mercado peruano. La presencia de ropa abaratada de China ha generado gran malestar ya que, en 2013, la venta de ropa producida en Gamarra se había reducido en una tercera parte. 


\section{Pensamiento Crítico Vol. 19. No 2}

De acuerdo a datos oficiales, entre 2009 y 2011, la industria de la confección en el Perú se contrajo en un $18.7 \%$ y el inventario acumulado subió a más del $30 \%$. Por otro lado, se observa que durante este mismo periodo, la importación de productos chinos se incrementó de 119 millones de piezas de vestir a 187 millones, cifra que abastecía al $80 \%$ de la demanda local, con precios que estaban entre el 37 y $38 \%$ por debajo del precio manufacturado en el mercado doméstico (Indecopi 2013b).

Los derechos antidumping sobre los tejidos de algodón y mixtos fueron impuestos en 1995 y complementados en 2002 y 2011. En 1995, ante los reclamos y solicitudes del sector por la importación de tejidos chinos que entraban a precios bajos, el Indecopi aplicó derechos antidumping a importaciones de tejidos de algodón y tejidos mixtos originarios de China (Resolución 005-95-CDS). Posteriormente a inicios de 2000, las importaciones de tejidos de China se incrementaron de manera significativa, igualmente a precios más bajos que los nacionales, con el consecuente incremento de las solicitudes para empezar las investigaciones por el perjuicio a la producción nacional de tela y confección de vestidos. Por ello, en 2002, Indecopi impone, nuevamente, medidas antidumping sobre las importaciones de vestidos de algodón y tejidos mixtos de China. Estas medidas fueron ampliadas en 2004 para tejidos planos de ligamento tafetán, popelina poliéster/algodón, estampados, blanqueados y teñidos con hilados. En 2008, a solicitud de la empresa importadora Colortex Perú, la CFDS dio inicio a un examen preliminar con el fin de determinar la necesidad de mantener, modificar o suprimir los derechos antidumping impuestos en 1995 sobre las importaciones de tejidos de algodón y tejidos mixtos de China. Mediante Resolución 135-2009/CFD, la Comisión decidió mantener la vigencia de tales derechos por un periodo de tres años (Comisión de Fiscalización de Dumping y Subsidios 2012).

Reaño Vega, miembro del Comité Textil de la SNI, señala que "el precio promedio de importación fue de 5.31 US $\$ / \mathrm{kg}$ CIF, en tanto que el precio de exportación para el mismo periodo fue de 15.69 US $\$ / \mathrm{kg}$ FOB. Esto indica que la mercancía textil y prendas de vestir están subvaluadas y entran a precios de dumping" (2012). Sin embargo, el crecimiento de las importaciones chinas en el rubro de textiles continuó, y por presiones políticas se logró que la salvaguardia solo esté vigente por once meses.

Si revisamos las resoluciones emitidas por el Indecopi sobre dumping y subsidios desde 1994 hasta fines de 2012, podemos observar (ver gráfico 2) que China es el país 


\section{Rubén Berríos}

que más quejas ha recibido sobre casos de dumping. También es evidente que varios de estos son casos que corresponden al sector textil y confección.

GRÁFICO 2

Resoluciones: Fiscalización de Dumping y Subsidios

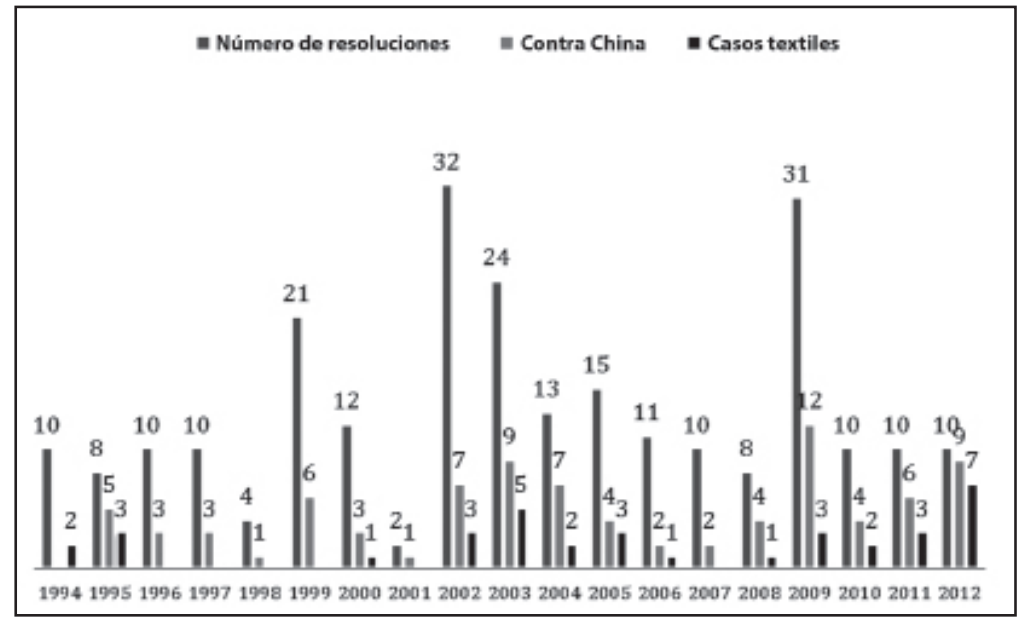

Fuente: Indecopi. Elaborado por el autor a base de datos del Indecopi, varios años.

Hasta marzo de 2013, Indecopi tenía cuatro procedimientos de investigación relacionados con textiles y prendas de vestir provenientes de este país (ver gráfico 2); y según la OMC China es el país al que más medidas antidumping e investigaciones se le han aplicado en el mundo (OMC 2008). Sus mismos funcionarios admiten que en 2007 existían "561 medidas antidumping en más de 30 países contra China" (Wang 2007:244). Igualmente, en varios países donde hay presencia del comercio chino las denuncias se han incrementado (Camacho 2011; Navarro 2008).

La considerable presencia de las empresas chinas en ciertos mercados para vender sus productos ha generado fricciones en el comercio internacional por las mismas razones que han experimentado las empresas peruanas y se han encontrado con iguales problemas para documentar los precios (Cepal 2012; Dussel Peters 2013; Santiso y Avendaño 2011). En textiles, China cuenta con la tercera parte de la producción global. (Ver gráfico 3). 
Pensamiento Crítico Vol. 19. No 2

GRÁFICO 3

Grandes productores de textiles y vestido

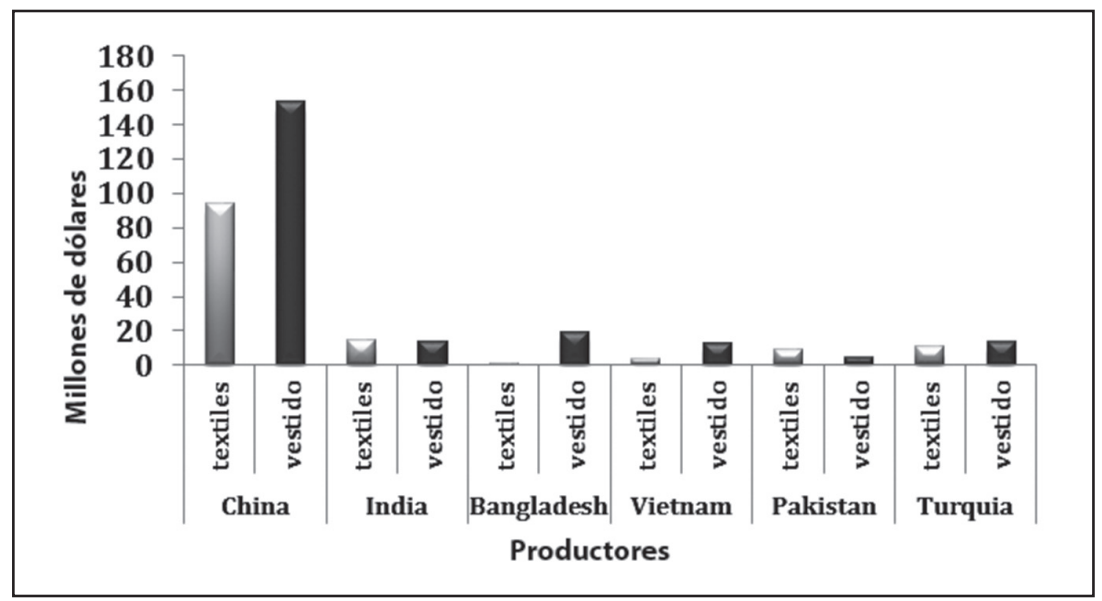

Fuente: OMC, 2014.

Lo problemático del asunto es que las estadísticas chinas sobre costos está distorsionada por los préstamos subsidiados, los mercados vinculados y la sobrevaluación forzada de yuan por el Banco de China (Haley y Haley 2013).

Ilustraremos el análisis con los casos del sector textil. Empezamos por señalar que la fabricación de textiles en el Perú se remonta a la época precolombina. En la etapa de desarrollo industrial temprana en este país, el sector textil tuvo un alto porcentaje de empleo y una mano de obra relativamente más intensiva que otros sectores; situación que se mantiene hasta la fecha. Según el Mincetur, se estima que laboran en él cerca de 400 mil personas. (Muñoz Marticorena 2006). En la actualidad es un sector de mucha relevancia en la economía peruana por ser uno de los sectores más dinámicos para la exportación (Centrum 2010). El sector textil y de confecciones en el Perú ha mostrado un rápido crecimiento y dinamismo y mantiene un alto nivel de integración a lo largo del proceso productivo. Los datos de 2013 indican que el sector textil representa aproximadamente el $9 \%$ de las exportaciones totales y casi la tercera parte de las exportaciones no-tradicionales. 


\section{Rubén Berríos}

Precisamente, para proteger este sector, Indecopi ha emitido las siguientes resoluciones:

La resolución de 2012 que resalta el caso de los tejidos tipo dril procedentes de China, sobre los cuales la CFDS dispuso de la aplicación de derechos antidumping. En el periodo analizado por la Comisión, de 2005 a 2009, se verificó que el precio de los tejidos se ubicaba en un nivel muy por debajo del nacional y ejercía presión a la baja en los precios de producción peruana. La decisión de la CFDS -emitida mediante resolución de mayo de 2011-, dispuso que se mantuvieran las medidas antidumping de 2009 por un periodo adicional de tres años. En el caso de tejidos tipo denim con un contenido de algodón de $85 \%$, se decidió que los derechos antidumping estarían vigentes solo hasta mediados de 2011 (Indecopi 2012).

La Resolución N. ${ }^{\circ}$ 083-20-2012/CFD-INDECOPI, emitida el 20 de junio de 2012, dio inicio al procedimiento de investigación por prácticas de dumping en importaciones de prendas de vestir y complementos (un importante sector de la economía nacional por su dinamismo exportador), confeccionados de tejidos de punto y tejidos planos procedentes de China. La Comisión identificó la existencia de prácticas de dumping que amenazaban a esta rama de la producción nacional. En la resolución se afirma que en 2011 las importaciones de origen chino al Perú registraron un margen de dumping promedio de $98 \%$ en el caso de prendas de vestir, $y$ hace notar que las importaciones originarias de China experimentaron un crecimiento de 47\% entre 2009 y 2011. Por otro lado, también se verificó la existencia de una subvaluación en el precio nacional. El precio de las confecciones chinas se ubica en un $85 \%$ por debajo del precio de los tejidos de punto producidos en el Perú. En ese mismo lapso, la subvaluación promedio de las prendas confeccionadas con tejidos planos fue de un 75\% (Indecopi 2013).

Todo esto corrobora que los productos nacionales en este sector se han visto seriamente afectados. Su participación en el mercado nacional cayó de 44\% a 37\% entre 2009 y 2011. Adicionalmente, las ventas internas sufrieron una caída de 16.4\%. El margen de utilidad también registró una disminución en relación con años anteriores 2007 y 2008. Según el documento del Indecopi (2013), hay indicios de que en el periodo revisado (2009-2011) las importaciones de China se realizaron a precios dumping. Es por ello que la CFDS dispuso el inicio de un proceso de investigación sobre la importación de prendas de vestir y complementos de China. 


\section{Pensamiento Crítico Vol. 19. No 2}

La importancia de esta investigación radica en que se enfoca en un sector que está conformado por 16 mil fabricantes, de los cuales el $97 \%$ son micro y pequeños empresarios, emplea gran número de trabajadores y es uno de los sectores más dinámicos para la exportación. Según el Mincetur (2009), el sector textil representa el $13 \%$ del PBI (Producto Bruto Interno) manufacturero y genera 1.5 millones de puestos de trabajo. De acuerdo con el Indecopi, 57\% de los derechos antidumping aplicados por esta institución a las importaciones, hasta comienzos de 2013, correspondían a productos chinos.

Mediante resolución 066-2013-CDS, la Comisión decidió mantener los derechos antidumping a la importación de tejidos estampados, pero suprimió las medidas para los tejidos con hilados de distintos colores y de filamentos sintéticos o artificiales de China. Asimismo, decidió mantener por un periodo adicional de dos años la vigencia de los derechos antidumping. Estos derechos antidumping fueron impuestos en 1995 y revisados en 2002 y 2009. En esta última ocasión tales medidas fueron prorrogadas hasta 2012. Tras la investigación, denominada 'examen por derechos compensatorios', se determinó que de tres productos investigados, a dos de ellos ya no correspondía extender el derecho.

Entretanto, la SNI ha decidido analizar la resolución aunque para iniciar una nueva investigación se debe esperar un año. La gerencia del Comité Textil de la SNI señala que existen razones para estudiar el caso porque en el sector textil estas confecciones chinas entran a un precio artificialmente bajo. Si bien por un lado se suprimirán los derechos antidumping a tejidos de las dos partidas arancelarias; por el otro, estos se mantendrán a las importaciones de tejidos mixtos estampados, tejidos de algodón y mezclas poliéster/ algodón, tejidos de algodón (denim) y tejidos de ligamento tafetán, todos originarios de China (Indecopi 2012, 2013a).

En diciembre de 2013, la CFDS de Indecopi dio por terminada una exhaustiva investigación que inició en junio del año anterior, donde se estimaba que había márgenes de dumping. Para iniciar la investigación de oficio la comisión nombrada por Indecopi tuvo en cuenta lo siguiente: "(i) Se estableció, de manera inicial, la existencia de márgenes de dumping en las importaciones de prendas y complementos de vestir procedentes de China, (ii) se determinó la existencia de indicios de daño importante sobre la rama de producción nacional en el periodo comprendido entre los años 2009 


\section{Rubén Berríos}

y 2011, según los términos establecidos en el artículo 3.1 del Acuerdo Antidumping". Las consideraciones que se tuvieron en cuenta fueron "las importaciones de prendas y complementos de vestir chinos experimentaron un incremento importante, tanto en términos absolutos como en relación con la producción nacional". Hay que tener presente que el principal proveedor textil del mercado interno en 2011 era China, con el $50 \%$ del mercado expresado en unidades de peso y el $57 \%$ de dicho mercado en número de prendas (Informe 031-2013/CFD-INDECOPI).

Al concluir el informe se determinó que había indicios de dumping pero solo aplicaría salvaguardias a cinco tipos de ropa bajo 34 subpartidas que impactan el desarrollo de la industria textil peruana (Indecopi 2013b). En este caso, las partes interesadas tuvieron oportunidad de expresar sus puntos de vista y evidencias sobre el efecto de las importaciones de China en el mercado nacional que, directa o indirectamente, genera aproximadamente 400000 empleos.

El levantamiento de las restricciones puede mantener el efecto negativo en la producción de textiles y confecciones del Perú. La presencia de un competidor tan grande como China puede afectar aún más el mercado nacional. Se debe resaltar que esta preocupación la comparte el presidente de la República, quien ha declarado que las empresas confeccionistas "están en peligro de salir del mercado por la competencia desleal de las importaciones chinas" (Barja 2013a). Asimismo, se ha enfatizado que el Gobierno adoptará las medidas necesarias para apoyar la competitividad de la industria textil. Mientras tanto, los gremios del emporio de Gamarra señalan que la importación de ropa china les ha quitado el $30 \%$ del mercado y que hay 3000 confeccionistas que están al borde de la quiebra (Barja 2013b).

\section{Los costos de producción y el 'precio chino'}

Por el lado de las importaciones, hay que tener en cuenta las siguientes consideraciones. El ingreso de productos de China, sin duda, beneficia a los importadores (mayormente extranjeros) y al consumidor nacional por el bajo precio, aunque a la larga no sea así por la calidad de la producción; sin embargo, no es beneficioso para los fabricantes nacionales, ya que muchas de estas importaciones han provocado el cierre de empresas del sector textil (Pérez 2012). Por ello, una de las principales preocupaciones 


\section{Pensamiento Crítico Vol. 19. № 2}

en las relaciones comerciales Perú-China es conocer cómo se consideran los costos de producción de los productos chinos.

Esta es la principal razón por la que China es vista como oportunidad, y a la vez, como una amenaza (Torres 2010). Al haber conquistado diversos mercados alrededor del mundo, muchos estudios sostienen que el sector de manufacturas en América Latina está siendo reemplazado por la producción china (Cepal 2012; Gallagher y Porzecanski 2010; González 2009). Harney (2008) y Navarro (2008) señalan que la ventaja del país asiático es lo que se llama el 'precio chino'. Esta denominación hace referencia a cómo los productos manufacturados en China se venden a precios muy por debajo del precio de sus competidores. En la actualidad dicho país produce el 70\% de los DVD y juguetes del mundo, y más de la mitad de las cámaras, bicicletas, teléfonos y calzado que se exporta al resto del mundo.

Desde que China abrió sus puertas al mundo en 1978, ha sido la economía que más rápido ha crecido y se ha convertido en el principal exportador del mundo. Asimismo, se ha hecho conocer como la 'fábrica del mundo', gracias a la mano de obra barata, especialmente en textiles y ropa de vestir (Cardenal y Araujo 2011; Devlin 2009; Dussel Peters 2013; Gallagher y Porzecanski 2010). De acuerdo con Wang (2006), la principal ventaja de China es el costo laboral barato, aunque en algunos sectores estos se han incrementado gradualmente. La fabricación de productos de consumo masivo y la exportación de estos productos chinos (textiles, juguetes, relojes, calzado) creció de manera acelerada porque a los consumidores les atraía el 'precio chino'. Harney (2008) advierte que este tiene una estructura de costos ad hoc, pues la producción se da en fábricas en las que los trabajadores laboran en condiciones infrahumanas y reciben bajísimos salarios por largas jornadas. Sin embargo, ¿̇cuál es el verdadero costo de la ventaja competitiva de China? El costo implica explotación laboral, contaminación y desplazamiento poblacional en ciertas regiones, ya que la mayor parte de estos trabajadores son migrantes temporales, todo esto apunta a un costo social aún mayor, con estimaciones impredecibles. En el gráfico siguiente podemos ver cómo, a pesar de que el precio internacional del algodón y la fibra sintética están por encima del precio chino $\mathrm{FOB}$, el precio de venta es menor que el costo de la materia prima textil. 


\section{Rubén Berríos}

\section{GRÁFICO 4}

Precios FOB de las importaciones originarias de China vs Precio internacional del algodón y poliéster (en índices)

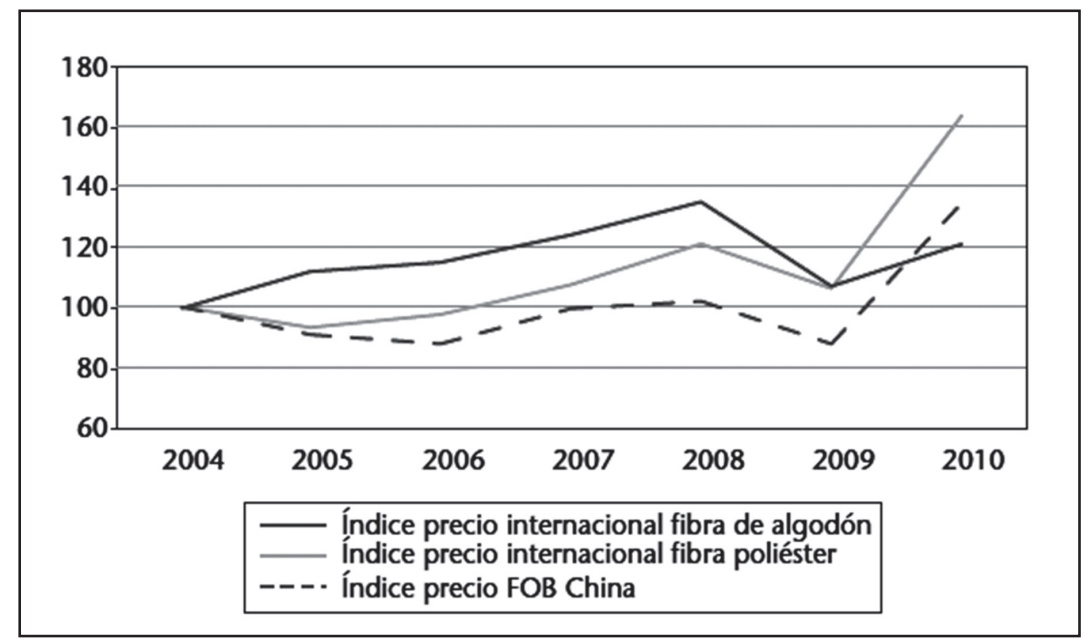

Fuente: SUNAT, COTTON ORG UN-COMTRADE.

Elaboración: ST-CFD/INDECOPI.

Además, el Estado chino ha hecho y continúa haciendo uso de los subsidios para apoyar algunas industrias y determinadas empresas para abrirse paso en ciertos mercados. Como se sabe, los subsidios pueden ser directos o indirectos, y asumen diversas formas: energía barata, normas de depreciación, mantenimiento de plantas, la forma de pagos al contado a los exportadores, créditos por impuestos, exoneración de impuestos o préstamos a bajo interés. Aunque los subsidios en sí no son una práctica ilegal, sí lo son si estos son usados para exportaciones (Haley y Haley 2013).

\section{Las importaciones chinas y sus efectos en el sector textil}

Es en el sector textil y de confecciones donde China mantiene su ventaja competitiva por ser el mayor productor del mundo. El Perú también tiene este sector bien desarrollado, pero se ha visto amenazado por el creciente ingreso de textiles y 


\section{Pensamiento Crítico Vol. 19. № 2}

confecciones de China y, más recientemente, también de la India. La feroz competencia de China en textiles y confecciones es resultado de su ventaja de costos de producción (Cepal 2012; Harney 2008; Cardenal y Araújo 2011). El abaratamiento de la ropa se debe, en gran medida, a la excesiva producción china que ha 'inundado' el mercado peruano y que también ha afectado las exportaciones peruanas de prendas de vestir. El resultado para el mercado local es: menor producción, cierres de talleres de confección, despido de trabajadores y la venta de estos artículos a precios más bajos. En la zona de Gamarra existen aproximadamente 17 mil fabricantes y distribuidores de productos textiles y confección. El temor que se percibe en estos centros de producción es que los productos chinos son muchas veces versiones de imitación barata de las marcas reconocidas, que son demandadas por los clientes de bajos ingresos y que inundan el mercado del vestido en el Perú.

De los aranceles de los sectores textiles y confecciones que el Perú negoció con China, cerca del 55\% fueron excluidos de la negociación en el TLC; esto representa aproximadamente unas dos terceras partes del valor de textiles y confecciones que el Perú importa desde aquel país. Frente a un sector que es subvencionado en China, el Perú se encuentra sin duda en una situación de desventaja.

Las acciones y políticas del Estado chino están diseñadas para influir en sus empresas (privadas y estales), haciéndolas más competitivas y exitosas para el mercado exterior. El Estado chino usa una variedad de instrumentos como la tasa de impuestos preferenciales, préstamos de bancos del Estado, protección comercial y otros tipos de subsidios para promover proyectos de exportación, y la intervención estatal se deja notar en las políticas preferenciales de comercio. El motor del crecimiento chino sigue siendo su sector exportador. A pesar de que China pertenece a la OMC, aquella no siempre aplica el fair play, ya que usa descuentos/reembolsos por exportaciones, políticas preferenciales para reinvertir, exoneración de impuestos por producir en zonas económicas especiales libres, excepción de arancel de exportación. Todo esto es consistente con el proyecto y estrategia comercial china orientada a promover las exportaciones (Haley y Haley 2013).

En las prácticas comerciales, China ha hecho uso de subsidios directos e indirectos en su política hacia las industrias de exportación. El tema del monto de los subsidios presenta un gran desafío debido a que no hay un cuadro preciso de la cantidad y valor. 


\section{Rubén Berríos}

Lo que sí se ha dejado notar es el apoyo estatal que reciben las empresas exportadoras chinas. ¿Qué tan grande es el problema? Se desconoce con certeza porque no hay datos precisos (Zahariadis 2008).

También hay artículos chinos que llegan no solo al Perú sino a muchos países por canales ilegales. Los impuestos que no se pagan significan enormes ganancias para el contrabando. Otra forma ilegal se manifiesta en el cambio de marca o certificado de origen de los productos chinos. Los artículos que entran por estos canales inusuales se venden aún a precios más bajos. Esto tiene un impacto negativo para las industrias manufactureras locales.

\section{Consideraciones finales}

La importación de productos chinos ha resultado ser muy popular en el Perú por sus bajos precios, incluso por debajo de lo que se cotizan localmente. Sin embargo, este hecho y la gran cantidad de productos que ingresan de contrabando han llevado a la SNI a denunciar la competencia desleal que afecta la producción nacional. De manera paralela, esta práctica comercial también ha causado efectos secundarios nocivos en el sector minero y textil.

En relación con lo denunciado, la CFDS consideró que en la etapa de evaluación inicial de las importaciones de prendas y complementos de vestir procedentes de China, se habían encontrado indicios suficientes sobre una presunta existencia de dumping, el que estaría causando un daño importante a la rama de producción nacional, según lo establecido en el artículo 3.1 del Acuerdo Antidumping.

Al emitir el documento final (Resolución N. 297-2013 del 22 de diciembre de 2013) la CFDS del Indecopi consideró metodológicamente, para efectos de la determinación del margen de dumping, el valor normal en función con el precio de exportación de las prendas de vestir y complementos originarios de China a USA. Se verificó la existencia de indicios de una situación especial de mercado en el sector de fabricación de prendas y complementos de vestir chino, por la presencia de distorsiones en los costos de producción que generaban que los precios de venta internos en dicho mercado no fuesen idóneos para efectuar una comparación con los precios de exportación al Perú (Indecopi 2013b). 


\section{Pensamiento Crítico Vol. 19. No 2}

De igual manera, para analizar la situación de la rama de la producción nacional se recurrió a la información proporcionada por entidades como la Sunat (Superintendencia Nacional de Administración Tributaria), el Ministerio de Trabajo y el INEI (Instituto Nacional de Estadística e Informática) "sobre los indicadores económicos agregados (como producción, ventas, participación de mercado, beneficios, salario y empleo) de las actividades económicas correspondientes... En relación con la producción nacional, la participación de mercado de las importaciones chinas, expresadas en número de prendas y unidades de peso, se incrementó en 6 y 7 puntos porcentuales en el periodo analizado."

A pesar de que entre 2009 y 2011 los precios de las importaciones chinas se incrementaron, aun así estaban muy por debajo de las importaciones colombianas similares, y tenían indicios de una subvaluación promedio ponderada de $85 \%$ para los tejidos de punto y $75 \%$ para los planos. Se ilustró que los efectos negativos sobre el sector textil peruano tenían como causa al incremento de las importaciones chinas "a precios presuntamente objeto de dumping, sin que se haya verificado la existencia de otros factores que pudieran explicar dicho daño".

Finalmente, considerando el punto de vista de la reacción estatal, el estudio detallado de la voluminosa Resolución N. ${ }^{\circ} 297$ (993 páginas) nos permite concluir que el Estado peruano debió mantener una vigilancia abierta y flexible para poder resolver denuncias de competencia desleal de manera más ágil. Sin embargo, hay que hacer notar la dificultad que existe debido a los plazos muy largos que se necesitan para probar las quejas sobre los precios dumping, principalmente por la naturaleza de los costos de producción involucrados en el llamado 'precio chino'. De igual manera, las medidas proteccionistas, ya sean subsidios a las exportaciones o créditos de seguros, que no son fáciles de verificar, deben ser investigadas, ya que actualmente el Estado peruano muestra poco interés por identificarlas debido en parte a la insuficiencia de personal técnico.

La presencia china en el Perú, sin embargo, no debe ser vista como una amenaza sino como una oportunidad. Una oportunidad si el Perú exporta productos con mayor valor agregado, si diversifica sus exportaciones, sin depender solamente casi exclusivamente de commodities. Asimismo, si el Perú compite con sus productos textiles de mayor calidad (algodón pima, por ejemplo), reconocida por los importadores 


\section{Rubén Berríos}

europeos y norteamericanos (no solamente por la calidad de las fibras, sino también por la mano de obra calificada que tiene), este sector tendría enormes ventajas competitivas. En la actualidad, si a algún sector empresarial le preocupa los términos políticos, está claro que China está menos interesada en promover una determinada ideología política y más abocada a supervisar sus respectivos negocios. Irónicamente el éxito del modelo chino se debe más al haber jugado bajo las reglas del capitalismo y no las del 'socialismo', y para facilitar su mayor presencia económica en el Perú y en otros países, ha hecho uso de la cooperación para el desarrollo y las inversiones recientes. En el caso peruano, el país asiático ha contado adicionalmente con el apoyo de su colonia, la que radica en el país desde hace más de 150 años.

A pesar de que el comercio con China ha generado beneficios mutuos, aún existe la preocupación entre los empresarios peruanos de que este país les ha quitado parte del mercado local y también los puede reemplazar en los mercados mundiales a los que exportan.

Tal como lo hemos señalado, si bien hemos sido beneficiados con nuestras exportaciones, la presencia económica de China ha generado una asimetría comercial que ha afectado uno de los principales sectores de manufacturas en el Perú como son textiles y confecciones.

\section{Referencias bibliográficas}

Appleyard, Dennis R. y Alfred J. Field. 2001. International Economics. McGraw Hill, New York.

Barja, Rocío. 2013a "Gobierno cree que 14,000 empresas confeccionistas están en riesgo". Gestión, Lima, 7 de agosto, p. 2.

Barja, Rocío. 2013b. "Gamarra alerta que hay 3,000 confeccionistas al borde de la quiebra". Gestión, Lima, 3 de setiembre, p. 12.

Berríos, Rubén. 2010. "Bridging the Pacific: Peru's Search for Closer Economic Ties with China”. En: Fernández Jilberto, Alex E. y Barbara Hogenboom (eds.). Latin America 


\section{Pensamiento Crítico Vol. 19. № 2}

Facing China: South-South relations beyond the Washington Consensus. Berghahn Books, N.Y., pp. 135-151.

Bustamante Olivares, Vicente. 2004. “¿Es China una verdadera amenaza?”. Quehacer 148, mayo/junio, p.66.

Camacho, Eduardo. 2011. "La SE denuncia a China ante la OMC". El Universal. México, 4 de noviembre.

Campodónico, Humberto. 2008. "Textiles chinos: importo barato y vendo caro". La República, Lima, 15 de diciembre, p. 12.

Cardenal, Juan Pablo y Heriberto Araújo. 2011. La silenciosa conquista china. Editorial Crítica, Barcelona.

Carbaugh, Robert J. 2013. International Economics. South-Western, Mason: Ohio

Centrum (Escuela de Negocios de la Pontifica Universidad Católica del Perú). 2010. Sector textil del Perú. Centrum, Lima, 27 setiembre.

Cepal 2012. China y América Latina y el Caribe: Hacia una relación económica y financiera estratégica.

Devlin, Robert. 2009. "El ascenso económico de China". En Riordan Roett y Guadalupe Paz (eds.). La presencia china en el hemisferio occidental: consideraciones para América Latina y Estados Unidos. Libros del Zorzal, Buenos Aires, pp. 139-183.

Dussel Peters, Enrique (coord). 2013. Economía, comercio e inversiones. Red ALACChina, UNAM (Universidad Nacional Autónoma de México), México D.F.

Gallagher, Kevin y Roberto Porzekanski. 2010. The Dragon in the Room: China and the Future of Latin American Industrialization. Stanford University Press, Palo Alto, California. 


\section{Rubén Berríos}

González, Francisco. 2009. "La ecuación económica: América Latina entre ganadores y perdedores. ¿Qué pueden hacer los perdedores?” En Riordan Roett y Guadalupe Paz (eds.). La Presencia china en el hemisferio occidental: consideraciones para América Latina y Estados Unidos. Libros del Zorzal, Buenos Aires, pp. 185-210.

González-Vicente, Rubén. 2012. "The Political Economy of Sino-Peruvian Relations: A New Dependency?" Journal of Current Chinese Affairs 41, pp. 97-131.

González-Vigil, Fernando. 2009. "El TLC China-Perú: una negociación ejemplar". Punto de Equilibrio 101, Lima, p. 30-31.

Haley, Usha C.V. y George Haley. 2013. Subsidies to Chinese Industry: State Capitalism, Business Strategy, and Trade Policy. Oxford University Press, New York.

Harney, Alexandra. 2008. The China Price: The True Cost of Chinese Competitive Advantage. The Penguin Press, London.

Indecopi (Instituto Nacional de Defensa de la Competencia y de la Protección de la Propiedad Intelectual). 2012. Informe de labores 2011, agosto. Comisión de Fiscalización de Dumping y Subsidios, Lima.

Indecopi (Instituto Nacional de Defensa de la Competencia y de la Protección de la Propiedad Intelectual). 2013a. Boletín Informativo N. ${ }^{\circ}$ 13, año 4, enero-marzo. Comisión de Fiscalización de Dumping y Subsidios, Lima.

Indecopi (Instituto Nacional de Defensa de la Competencia y de la Protección de la Propiedad Intelectual). 2013b. Informe N. ${ }^{\circ}$ 031-2013/CFD-Indecopi, 4 diciembre. Comisión de Fiscalización de Dumping y Subsidios, Lima.

Infante Alosilla, Juan. 2004. "El cuco ya está entre nosotros". Quehacer 148, mayo/ junio, p. 62-65.

Infante A., Juan. 2002. "Gamarra: el Perú de los peruanos". Quehacer 136, mayo/junio, p. 66-71. 


\section{Pensamiento Crítico Vol. 19. № 2}

$\mathrm{Li}$, Yuefen. 2007. "Why is China the World's Number One Anti-Dumping Target?" En Bibek Debroy y Debashis Chakraborty (eds.) Anti-Dumping: Global Abuse of Trade Policy Instrument, Liberty Institute, New Delhi, pp. 133-154.

Mann, Stefanie. 2006. Peru's Relations with Pacific Asia. LIT Verlag, Berlín.

Mendoza, Armando. 2010. “TLC con China: ¿̇sacrificando al sector textil?” La República, Lima, 11 de marzo, p. 13.

Mincetur (Ministerio de Comercio Exterior y Turismo). 2007. Perú-China Free Trade Agreement, Joint Feasibility Study. Mincetur, Lima.

Mincetur (Ministerio de Comercio Exterior y Turismo). 2009. Estudios de mercado e identificación de oportunidades que enfrenta el sector textil para prendas de vestir y accesorios de algodón, alpaca y mezclas en España, Reino Unido y Alemania. Proyecto UE-Perú/PENX, sector textil y confecciones. Mincetur, Lima.

Muñoz Marticorena, William. 2006. Perú: Tradición textil y competitividad internacional. Fondo Editorial de la Universidad Sedes Sapientiae, Lima.

Navarro, Peter. 2008. The Coming China Wars. FT Press, Upper Saddle River, Nueva Jersey.

OMC (Organización Mundial de Comercio). 2008. Examen de las políticas comerciales, informe de la secretaria. China. OMC, Ginebra, 16 de abril.

Pérez, Silvia. 2012. "Sector textil en problemas por dumping," La República, Lima, 9 de setiembre, p. 22.

Quispe, Edika. 2009. "Hacer negocios en China. Entrevista a Marcus Lee". Punto de Equilibrio 100, p 62-64.

Reaño Vega, Martín. 2012. "Situación actual del sector textil peruano". Industria Peruana 872, Sociedad Nacional de Industrias, Lima, setiembre, pp. 12-14. 


\section{Rubén Berríos}

Santiso, Javier y Rolando Avendaño. 2011. "Economic Fundamentals of the Relationship". En Adrian Hearns y Luis León-Manríquez (eds.). China Engages Latin America: Tracing the Trajectory. Lynne Rienner Publishers, Boulder, Colorado.

Salvatore, Dominick. 2007. International Economics. John Wiley \& Sons, Hoboken, Nueva Jersey.

Sanborn, Cynthia A. y Víctor Torres C. 2009. La economía china y las industrias extractivas: desafíos para el Perú. Universidad del Pacifico, Lima.

Torres, Víctor C. 2010. El TLC con China: ¿Oportunidad o amenaza? Posibles implicancias para el Perú. Serie Cuaderno Globalización con Equidad No 5. RedGe, Lima.

Torres-Zorrila, Jorge y Enrique Woll Battistini. 2007. Perú-China: Comercio, Inversión y transporte. Centrum PUCP, Lima.

Wang, Shen-Way. 2007. China's Ascendancy: An Opportunity or a Threat? What Every American Should Know About China. International Publishing House for China's Future, Washington, DC.

Wang, Yanling. 2006. "Cheap Labor and China's Export Capacity". En Kevin H Zang (ed.). China as the World Factory. Routledge, Nueva York, pp. 69-81.

Webb, Richard; Josefina Camminati y Raúl León. 2005. "Mecanismos antidumping y salvaguardias en el Perú". En J. Michael Finger y Julio J. Nogués (eds.). Salvaguardias y antidumping en la liberación del comercio en América Latina: combatiendo el fuego con fuego. Siglo XXI, Buenos Aires, pp. 45-75.

Wise, Carol. 2012. "Tratados de libre comercio al estilo chino: los TLC Chile-China y Perú-China," Apuntes 71, Vol. 39, segundo semestre, pp.161-188.

Viner, Jacob. 1966. Dumping: A Problem in International Trade. Augustus M. Kelley Publishers, Nueva York.

Zahariadis, Nikolaos. 2008. State Subsidies in the Global Economy. Palgrave, London. 